\title{
Pedoman Tata Kelola Teknologi Informasi Menggunakan IT Governance Design Frame Work (Cobit) Pada PT. X
}

\author{
I Ketut Adi Purnawan \\ Program Studi Teknologi Informasi Universitas Udayana \\ Jalan Kampus Bukit Jimbaran, Bali, Indonesia \\ dosenadi@yahoo.com
}

\begin{abstract}
Abstrak
Penerapan Teknologi Informasi (TI) pada suatu organisasi memerlukan biaya yang besar dengan resiko kegagalan yang tinggi [1]. Pengelolaan data merupakan hal yang dilakukan secara terus menerus oleh organisasi yang disertai pengawasan dan pengukuran atas pencapaian yang telah dilakukan untuk memenuhi aspek integritas, availabilitas serta keamanan [2]. Dalam penelitian ini menggunakan COBIT sebagai frame work dalam penyusunan pedoman tata kelola teknologi informasi PT. X khusus pada DS11 yang memfokuskan pada pengelolaan data mengenai tingkat kepedulian manajemen (management awareness) dan tingkat kematangan (maturity level). Hasil kajian dan analisis menunjukkan bahwa tingkat kepedulian manajemen (management awareness) PT. $X$ berada pada tingkat yang cukup dan tingkat kematangan (maturity level) saat ini (as is) berada pada level 3 (defined process) dan tingkat kematangan yang diharapkan berada pada level 5 (optimised). PT. X telah mengakui bahwa data merupakan aset penting yang harus dikelola.
\end{abstract}

Kata kunci: IT Design Frame Work, COBIT, Management Awareness, Maturity Level.

\begin{abstract}
Implementation of Information Technology (IT) in an organization require significant costs with high risk of failure [3]. Managing data is a matter that must be done continuously by the organization and accompanied by monitoring and measurement of achievement that has been done as to meet the aspect of integrity, availablility. In this study using COBIT as a frame work in preparing the guidelines for information technology governance at PT. $X$ on DS11, which focuses on management of data about the level of concern for management (management awareness) and maturity level (maturity level). The study and analysis indicates that the level of concern for management (management awareness) PT. $X$ already on a fairly level and maturity level for the current maturity level (as is) at level 3 (defined process) and to the expected level of maturity located at level 5 (optimized). From the overall study results showed that PT. $X$ has recognized that the data is an important organizational asset.
\end{abstract}

Keywords: IT Design Frame Work, COBIT, Management Awareness, Maturity Level.

\section{Pendahuluan}

Penerapan teknologi informasi (TI) pada suatu organisasi memerlukan biaya yang cukup besar dengan resiko kegagalan yang tidak sedikit [4]. Penerapan teknologi infornasi memberikan peluang atau kesempatan terjadinya transformasi dan produktifitas bisnis yang telah berjalan [5]. Penyebaran sumber daya informasi pada PT. X menjadi kebutuhan yang sangat penting dimana akan membantu dalam proses pengambilan keputusan berkaitan dengan kebijakan strategis PT. X dalam menghadapi kemajuan dan persaingan global. Dengan pengelolaan data secara efektif dapat memenuhi kebutuhan perusahaan dalam mengoptimalkan penggunaan informasi dan memberikan jaminan bahwa informasi yang 
diperlukan senantiasa tersedia. Pengelolaan tatakelola teknologi informasi menggunakan kerangka kerja COBIT yang memberikan kebijakan yang jelas dan praktik yang baik dalam tatakelola teknologi informasi dengan membantu manajemen senior memahami dan mengelola resiko terkait $\mathrm{TI}[6]$.

\section{Metodologi Penelitian}

Penelitian ini dilakukan pada PT. X, pemilihan didasari atas pertimbangan bahwa PT. X merupakan perusahaan yang telah memanfaatkan Teknologi Informasi dalam proses bisnis perusahaan dan telah menerapkan ISO 9002-2000 dalam pelaksanaan manajemennya.

Pihak-pihak yang dipilih sebagai responden yang menjadi target penelitian ini meliputi: pimpinan perusahaan, managemen dan karyawan yang ada diperusahaan tersebut dengan target seluruh karyawan mengisi kuesioner.

Penelitian ini menggunakan data primer. Data primer merupakan data yang diperoleh langsung dari responden. Data primer diperoleh melalui metode survei yaitu kuesioner. Metode pengumpulan data primer dengan metode survei didasarkan pada kriteria yaitu tujuan penelitian, keakuratan, metode survei dan tersedianya sumber data [4]. Selain itu, penelitian survei dikembangkan dengan pendekatan positivis dengan memberikan pertanyaan pada responden mengenai keyakinan, pendapat, karakteristik dan perilaku dimasa lalu atau masa kini. Pengolahan data dilakukan dengan menggunakan statistik untuk mendapatkan hasil dari kuesioner yang telah dikumpulkan.

\section{Kajian Pustaka}

Penelitian tentang COBIT dalam bidang pendidikan dalam hal ini perguruan tinggi sudah pernah dilakukan. Salah satunya dilakukan oleh Solikin, program Magister Sistem Informasi, Departemen Teknik Informatika Institut Teknologi Bandung yang meneliti tentang Pengelolaan Informasi Sekolah Tinggi Manajemen Informatika dan Komputer "AMIKBANDUNG" ("STIMIK BANDUNG"). Dari hasil penelitiannya didapatkan bahwa pengelolaan teknologi informasi sudah dilakukan, akan tetapi belum dikelola dengan menggunakan pendekatan dan metode terstruktur, sehingga sulit untuk mengukur seberapa besar peranan teknologi informasi dalam mendukung pencapaian perusahaan secara efektif dan efisien [7].

Riasetiawan dalam penelitian tentang pembuatan tatakelola TI di Universitas Gadjah Mada menyimpulkan bahwa IT Governance Design Framework merupakan kerangka desain yang berperan dalam memahami, mendesain, mengkomunikasikan dan memelihara tatakelola TI. Fokus IT Governance Design Framework adalah menetapkan strategi organisasi yang diwujudkan dengan strategi TIK-nya, memberikan perhatian pada perilaku organisasi dan pengabdosian TI dalam organisasi tersebut, memperhatikan dan dan melakukan harmonisasi dengan tatakelola yang lain. IT Governance Desicions Arrangement Metric digunakan sebagai alat memetakan tipe pengambilan keputusan TI untuk area TI tertentu. IT Governance Desicions Arrangement Metric merupakan bentuk kolaboratif antara pihak-ihak yang terlibat dan pihak yang mengambil keputusan terkait area TI tertentu. Agar IT Governance Design Framework dan IT Governance Desicions Arrangement Metric dapat mengakomodasi tatakelola yang efektif dibuat kerangka kelola TI yang terdiri atas kebijakan umum TI, standar TI dan prosedur operasional [8]. 


\section{Hasil dan Pembahasan}

Analisa identifikasi resiko dilakukan terhadap pengumpulan data sebagai hasil kuesioner I Management Awareness. Dari pelaksanaan survei ini, diperoleh jawaban sebanyak jumlah kuesioner yang telah didistribusikan kepada para responden yang ada di PT. X. Dari hasil jawaban responden, dibuat suatu rekapitulasi yang menggambarkan kecenderungan tingkat pemenuhan, kinerja, maupun pencapaian yang sekarang berlangsung di PT. X terhadap beberapa obyek pertanyaan, pemenuhan DCO maupun indikator yang terkait pada proses pengelolaan data secara umum, yang dapat dilihat pada Tabel 1.

Tabel 1. Rekapitulasi jawaban kuesioner I Management Awareness

\begin{tabular}{clccc}
\hline \multirow{2}{*}{ No } & \multicolumn{1}{c}{ Obyek Pertanyaan } & \multicolumn{2}{c}{ Distribusi Jawaban } \\
& & $\mathbf{L}(\%)$ & $\mathbf{M}(\%)$ & $\mathbf{H}(\%)$ \\
\hline 1 & Kebutuhan Bisnis untuk Manajemen Data & 11.11 & 61.11 & 27.78 \\
2 & Pengaturan Penyimpanan & 33.33 & 38.89 & 27.78 \\
3 & Media Library & 55.56 & 33.33 & 11.11 \\
4 & Penghapusan data/Disposal & 16.67 & 83.33 & 0 \\
5 & Backup dan Restore & 16.67 & 44.44 & 38.89 \\
6 & Kebutuhan Keamanan Manajemen Data & 16.67 & 61.11 & 22.22 \\
7 & Pengujian Terhadap Media Backup & 55.56 & 44.44 & 0 \\
8 & Kecepatan Proses Restorasi & 55.56 & 33.33 & 11.11 \\
9 & Keberhasilan Proses Restorasi & 27.78 & 55.56 & 16.67 \\
10 & Keamanan Data Sensitif Setelah Disposal & 44.44 & 55.56 & 0 \\
11 & Penanganan insiden kapasitas & 38.89 & 33.33 & 27.78 \\
12 & Keandalan Sistem karena Proses & 11.11 & 66.67 & 22.22 \\
13 & Kepuasan Pengguna atas Ketersediaan & 5.56 & 83.33 & 11.11 \\
14 & Kepatuhan pada Aspek Hukum/aturan & 22.22 & 66.67 & 11.11 \\
& & & \\
& TOTAL & $\mathbf{2 8 . 5 7 2 8}$ & $\mathbf{5 4 . 3 6 4 2}$ & $\mathbf{1 6 . 2 7}$ \\
\hline
\end{tabular}

Secara umum rekapitulasi hasil kuesioner I management awareness seperti terlihat pada Tabel 1, dapat ditarik suatu kecenderungan yang merefleksikan fakta dilapangan yaitu bahwa:

a. Sebagian besar responden, $54,37 \%$ responden menyatakan pendapat, opini atau kesadarannya bahwa tingkat kinerja dalam proses pengelolaan data adalah cukup atau sedang.

b. Sebanyak $28,57 \%$ responden mengemukakan pendapatnya kinerja proses pengelolaan data adalah kurang atau rendah.

c. Hanya $16,27 \%$ responden yang menyatakan bahwa praktik pengelolaan data yang sekarang berlangsung sangat baik dan relatif telah memenuhi harapan.

Untuk dapat mendeskripsikan secara jelas hasil kajian tentang kinerja proses DS11, khususnya pada pemenuhan kriteria-kriteria dalam proses DS11 yang tertuang dalam DCO, maka dilakukan pemetaan terhadap jawaban kuesioner I dengan nilai kinerja yang merefleksikan secara kuantitatif tingkat kinerjanya, seperti terlihat pada Tabel 2.

Tabel 2. Pemetaan jawaban kuesioner I dan detail control objectives (DCO)

\begin{tabular}{clcc}
\hline No & \multicolumn{1}{c}{ Jawaban } & Nilai Kinerja & Tingkat Kinerja \\
\hline 1 & L (Low) & 1,00 & Kurang \\
2 & M (Medium) & 2,00 & Sedang \\
3 & H (High) & 3,00 & Baik \\
\hline
\end{tabular}

Dengan merujuk Tabel 2 dapat diperoleh nilai kinerja terhadap pemenuhan DCO tersebut secara kuantitatif, yang dapat dilihat pada Tabel 3. 
Tabel 3. Tingkat kinerja Detailed Control Objectives

\begin{tabular}{|c|c|c|}
\hline No & Detailed Control Objectives (DCO) & Nilai Kinerja \\
\hline 1 & Kebutuhan bisnis untuk manajemen data (DS11.1) & 2.17 \\
\hline 2 & Pengaturan penyimpanan (DS11.2) & 1.94 \\
\hline 3 & Media library(DS11.3) & 1.56 \\
\hline 4 & Penghapusan data/disposal(DS11.4) & 1.83 \\
\hline 5 & Backup dan Restore (DS11.5) & 2.22 \\
\hline \multirow[t]{2}{*}{6} & Kebutuhan keamanan manajemen data (DS11.6) & 2.06 \\
\hline & Rata-rata & 1.96 \\
\hline
\end{tabular}

Secara keseluruhan berdasarkan Tabel 3 dapat ditarik suatu kesimpulan, bahwa:

a. Tingkat pemenuhan DCO pada proses pengelolaan data adalah sedang namun masih perlu ditingkatkan, dengan nilai rata-rata nilai kinerja dalam proses pengelolaan data adalah sebesar 1,96, seperti direpresentasikan dalam diagram radar pada Gambar 1 .

b. Hasil tersebut didukung dengan hasil kuesioner secara keseluruhan seperti pada Tabel 4.

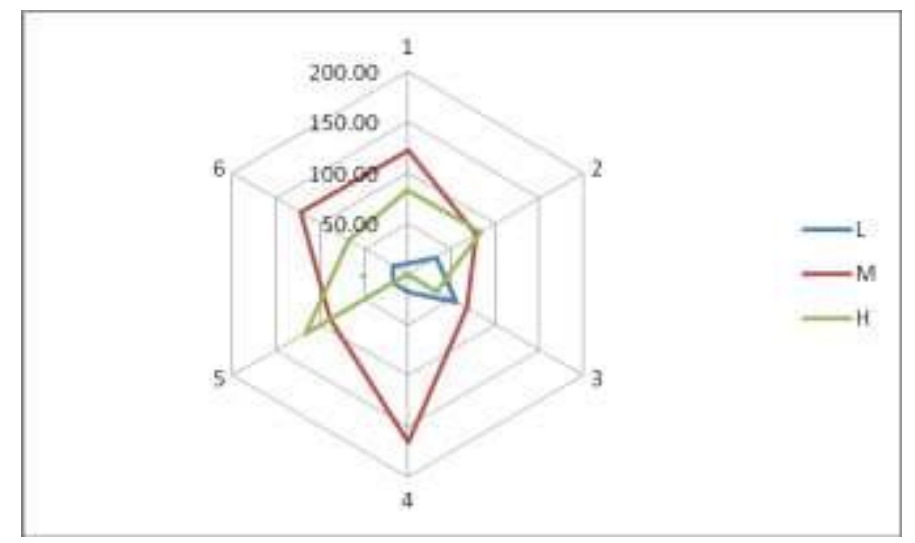

Gambar 1. Representasi tingkat pemenuhan DCO pada proses pengelolaan data

Dari pelaksanaan survei kuesioner II Maturity Level, diperoleh jawaban atas kuesioner tersebut sebanyak jumlah kuesioner yang didistribusikan kepada para responden. Dari jawaban responden tersebut selanjutnya dibuat rekapitulasi, seperti terlihat pada Tabel 5 dan dinyatakan dalam grafik pada Gambar 2, yang secara garis besar dapat memberikan gambaran kecenderungan suatu tingkat kematangan atas beberapa atribut, pada proses pengelolaan data di PT. X 
Tabel 5. Rekapitulasi distribusi jawaban kuesioner II Maturity Level

\begin{tabular}{|c|c|c|c|c|c|c|c|c|}
\hline \multirow{2}{*}{ No } & \multirow{2}{*}{ Atribut } & \multirow{2}{*}{ Status } & \multicolumn{6}{|c|}{ Distribusi Jawaban } \\
\hline & & & $a(0) \%$ & $b(1) \%$ & $c(2) \%$ & $d(3) \%$ & $\mathrm{e}(4) \%$ & $f(5) \%$ \\
\hline \multirow{2}{*}{1} & \multirow{2}{*}{$A C$} & as is & 5.56 & 33.33 & 38.89 & 5.56 & 11.11 & 5.56 \\
\hline & & to be & 0 & 5.56 & 16.67 & 11.11 & 5.56 & 61.11 \\
\hline \multirow{2}{*}{2} & \multirow{2}{*}{ PSP } & as is & 5.56 & 0 & 38.89 & 38.89 & 16.67 & 0 \\
\hline & & to be & 0 & 5.56 & 22.22 & 5.56 & 0 & 66.67 \\
\hline \multirow{2}{*}{3} & \multirow{2}{*}{ TA } & as is & 0 & 16.67 & 44.44 & 22.22 & 16.67 & 0 \\
\hline & & to be & 0 & 0 & 5.56 & 16.67 & 22.22 & 55.56 \\
\hline \multirow{2}{*}{4} & \multirow{2}{*}{ SE } & as is & 0 & 0 & 22.22 & 61.11 & 16.67 & 0 \\
\hline & & to be & 0 & 0 & 0 & 0 & 22.22 & 77.78 \\
\hline \multirow{2}{*}{5} & \multirow{2}{*}{ RA } & as is & 0 & 16.67 & 22.22 & 50 & 5.56 & 5.56 \\
\hline & & to be & 0 & 0 & 0 & 0 & 38.89 & 61.11 \\
\hline \multirow{2}{*}{6} & \multirow{2}{*}{ GSM } & as is & 5.56 & 0 & 38.89 & 44.44 & 11.11 & 0 \\
\hline & & to be & 0 & 0 & 0 & 0 & 33.33 & 66.67 \\
\hline & As & & 2.78 & 11.11 & 34.26 & 37.04 & 12.96 & 1.85 \\
\hline & To & & 0 & 1.85 & 7.41 & 5.56 & 20.37 & 64.81 \\
\hline
\end{tabular}

Secara umum dari rekapitulasi hasil kuesioner II Maturity Level pada Tabel 5 dapat diperoleh suatu kecenderungan fakta dilapangan tentang tingkat kematangan proses pengelolaan data, baik saat ini (as is) maupun yang diharapkan (to be) sebagai berikut:

a. Sebagian besar responden 37,04 \% memberikan jawaban "d" atas pertanyaan yang berorientasi masa kini (as is).

b. Pada jawaban atas pertanyaan yang berorientasi masa depan (to be), sebagian besar responden, $64,81 \%$ memberikan jawaban "f".

Adanya kecenderungan tersebut lebih jelas ditunjukan pada Gambar 2, dimana posisi puncak kurva lonceng as is lebih dekat pada jawaban "d" dan posisi puncak kurva lonceng to be lebih dekat pada jawaban "f".

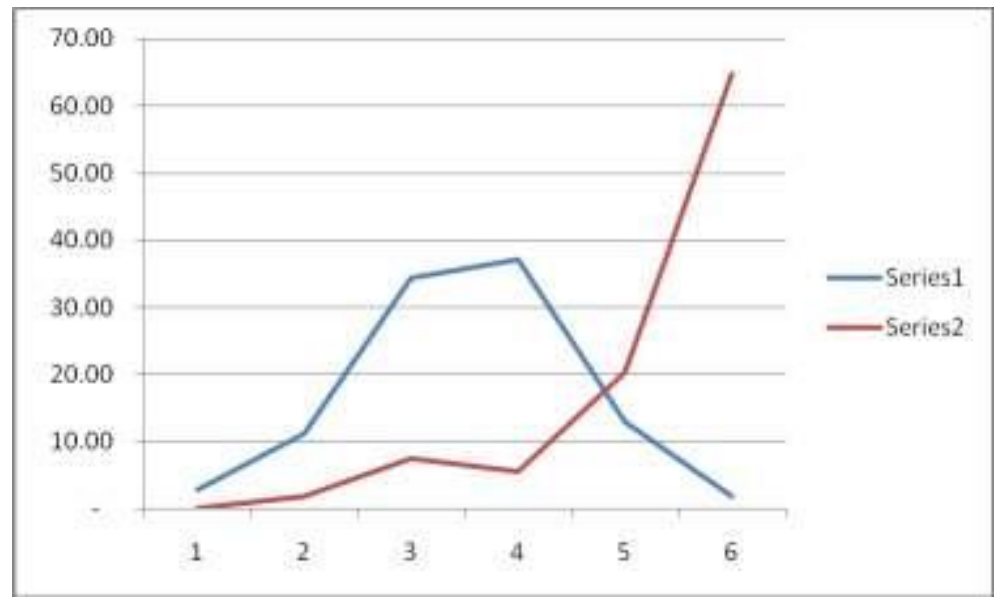

Gambar 2. Representasi Jawaban Kuesioner II Maturity Level

\section{Kesimpulan}

Hasil penelitian menunjukan bahwa data merupakan aset penting yang harus dikelola dengan baik agar proses bisnis organisasi berjalan dengan baik. Tingkat kepedulian (awareness) manajemen PT. X berada pada tingkat sedang/medium (54,37\%) yang merupakan indikasi yang baik dalam hal kepedulian terhadap data. 
Tingkat kematangan dalam hal pengelolaan data yang berorientasi pada saat ini (as is) berada pada level $3(37,04 \%)$ dan untuk tingkat kematangan yang diharapkan (to be) berada pada level $5(64,81 \%)$. Peningkatan tingkat kematangan dalam hal pengelolaan data dapat dilakukan secara bertahap dengan memperhatikan tatakelola yang dihasilkan dari kajian penelitian dan melakukan pengawasan (monitoring) secara terus-menerus dalam pelaksanaannya.

\section{Daftar Pustaka}

[1] Sugiyono, Metodologi Penelitian Bisnis, 7th ed. Bandung: Alfabeta, 2004.

[2] T. Josua, Merancang IT Governance dengan COBIT \& Sarbanes-Oxley dalam Konteks Budaya Indonesia, 2006.

[3] Albarda, "Penelitian tentang Strategi Implementasi Pemanfaatan Teknologi Informasi Untuk Tata Kelola Organisasi (IT-Governance)," 2006.

[4] P. Laplante and T. Costello, CIO Wisdom II More Best Practice. Pearson Education Inc., 2006.

[5] J. C. V. Henderson, "N. Strategic Alignment: Leveraging Information Technology for Transforming," IBM Syst. J., vol. 32, no. 1, pp. 472-484, 1993.

[6] I. G. I. and the O. of G. Commerce, Aligning COBIT, ITIL, and ISO 17799 for Business. 2005.

[7] Solikin, "Pengelolaan Informasi Sekolah Tinggi Manajemen Informatika dan Komputer," Institut Teknologi Bandung, 2004.

[8] Riasetiawan, "Pembuatan tatakelola TI di Universitas Gadjah Mada dengan IT Governance Design Framework," Universitas Gadjah Mada, 2007. 